\title{
Soroprevalência e fatores de risco para infecção pelo Helicobacter pylori
}

\author{
Seroprevalence and risk factors for Helicobacter pylori infection
}

\author{
Francisco de Agostinho Júnior*
}

Mo soroprevalência do Helicobacter pylori em pré-escolares e escolares e analisam os fatores de risco nas crianças com sorologia positiva. Desde os estudos iniciais ${ }^{1}$, mostrando a colonização de bactérias semelhantes às do gênero Campylobacter (grego = bastonete encurvado) na mucosa gástrica, associada a alterações histológicas, tem-se atribuído a esta bactéria, mais tarde denominada ${ }^{2}$ de Helicobacter pylori, a participação na gênese da gastrite, da úlcera péptica, do adenocarcinoma gástrico e do linfoma de Malt. Em crianças, a relação entre Helicobacter pylori e gastrite antral foi descrita pela primeira vez por Czinn et al. ${ }^{3}$, e em seguida por Drumm et al. ${ }^{4} \mathrm{O}$ Helicobacter pylori é uma bactéria que apresenta características genéticas e fatores de virulência que lhe permitem sobreviver em um nicho hostil e incomum de $\mathrm{pH}$ muito ácido, que é o estômago humano. Esta bactéria é tão bem adaptada ao estômago humano que, após a primeira infecção, que pode ocorrer precocemente na infância, ele estabelece uma infecção crônica para a vida toda.

Como bem abordaram Moraes et al., embora seja fato conhecido que o Helicobacter pylori tem sido isolado no mundo todo, no Brasil os estudos sobre a prevalência da infecção, principalmente em crianças, são poucos e se limitam a algumas regiões. Embora o conhecimento sobre a sua epidemiologia em crianças seja limitado, já que a maioria dos estudos foi realizada em adultos e também porque há dificuldades em se saber quando a infecção é inicialmente adquirida, pode-se afirmar que, semelhantemente ao que ocorre com outros patógenos entéricos, a infância representa a fase de máxima suscetibilidade para infecção pelo Helicobacter pylori ${ }^{5}$.

Os estudos epidemiológicos têm mostrado que aproximadamente $50 \%$ da população mundial está infectada com este microorganismo, sendo que a sua prevalência (medida de uma dada condição na comunidade) é maior em países

\footnotetext{
* Doutor em Medicina pela Universidade de São Paulo, Área de Pediatria. Responsável pelo Serviço de Gastroenterologia Infantil da Faculdade de Medicina de Marília, SP.
}

em desenvolvimento do que em países desenvolvidos ${ }^{6}$. Em crianças abaixo de 10 anos de idade, a taxa de prevalência é de aproximadamente 0,5 a $5 \%$ em países desenvolvidos, e de 13 a 60\% em países em desenvolvimento. A incidência (taxa de aquisição) da infecção pelo Helicobacter pylori é estimada em 3 a $10 \%$ ao ano nos países em desenvolvimento, e de $1 \%$ nos países desenvolvidos. A incidência após os 10 anos é aproximadamente de $1 \%$ ao ano, tanto em países desenvolvidos como em desenvolvimento. Observamos que os resultados obtidos por Moraes et al. quanto à prevalência do Helicobacter pylori, de $25,8 \%$ nos pré-escolares e de $39,4 \%$ nos escolares, considerando a região de Pernambuco, estão de acordo com a literatura mencionada.

Quanto aos fatores de risco que influenciam a prevalência e a transmissão do Helicobacter pylori, estudados com detalhes por Moraes et al., encontramos na literatura que a presença desta bactéria está associada à baixa condição socioeconômica, maior densidade de moradia, baixo nível educacional, baixas condições de saneamento básico e fatores dietéticos ${ }^{7}$. Além disso, alguns autores mencionam outros fatores que podem ter participação no desenvolvimento da infecção pelo $\mathrm{He}$ licobacter pylori na mucosa gástrica, como sexo, grupos sanguíneos, genótipos HLA e secreção ácida.

Apesar desses dados, há pouco entendimento de como esse microorganismo é transmitido dentro da comunidade. O único fato aceito é o de que o Helicobacter pylori precisa entrar para o estômago através da boca. A bactéria é não invasiva, e, portanto, não pode chegar à mucosa gástrica por outra via.

Vale ressaltar que o método diagnóstico, sorologia, usado por Moraes et al., dosando anticorpo anti-Helicobacter pylori da classe IgG, embora não invasivo, não pode ser usado como teste diagnóstico primário, pois não pode fornecer prova de uma infecção existente. É mais eficaz, portanto, para avaliações epidemiológicas ou para triagens. A base do método sorológico é a capacidade do Helicobacter pylori para despertar uma resposta imune, tanto local quanto sistêmica. O valor da dosagem do anticorpo antiHelicobacter pylori das classes IgA e IgM é controvertido, 
entretanto, não parece ser um indicador eficaz na população pediátrica. Além de não poder ser o único teste diagnóstico, a sorologia não pode ser o método usado para monitorizar os efeitos imediatos da terapia antibacteriana, devido ao retardamento entre a erradicação bacteriana e o declínio dos anticorpos ${ }^{8}$.

\section{Referências bibliográficas}

1. Warren JR, Marshall BJ. Unidentified curved bacilli on gastric epithelium in active chronic gastritis [letter]. Lancet 1983;1: 1273-5.

2. Goodwin CS, Armstrong JA, Chilvers T, Peters M, Collins MD, Sly L, et al. Transfer of Campylobacter pylori and Campylobacter mustelae to Helicobacter ge. Nov As Helicobacter pylori comb. nov. and Helicobacter mustelae comb. nov., respectively. Int J Syst Bacteriol 1989;39:397-405.
3. Czinn SJ, Dahms BB, Jacobs GH, Kaplan B, Rothstein FC. Campylobacter-like organisms in association with symptomatic gastritis in children. J Pediatr 1986;109:80-3.

4. Drumm B, Sherman P, Cutz E, Karmali M. Association of Campylobacter pylori on the gastric mucosa with antral gastritis in chidren. N Engl J Med1987;316:1557-61.

5. Graham DY, Malaty HM, Evans DG, Evans DJ Jr, Klein PD, Adam E. Epidemiology of Helicobacter pylori in an asymptomatic population in the United States: effect of age, race, and socioeconomic status. Gastroenterology 1991;100:1495-501.

6. Mitchell HM, Li YY, Hu PJ, Liu Q, Chen M, Du GG, et al. Epidemiology of Helicobacter pylori in southern China: identification of early childhood as the critical period for acquisition. J Infect Dis 1992;166:149-53.

7. Toyonaga A, Okamatsu H, Sasaki K, Kimura H, Saito T, Shimizu S, et al. Epidemiological study on food intake and Helicobacter pylori infection. Kurume Med J 2000;47:25-30.

8. Bujanover Y, Reif S, Yahav J. Helicobacter pylori e doença péptica no doente pediátrico. Clín Pediatr Am Norte 1996;1: 215-35. 